\title{
Problematização e reconhecimento de teorias e práticas de professores em formação para o ensino de Ciências com foco no educar pela pesquisa
}

\author{
Problematization and recognition of theories and practices of teachers in \\ formation for the teaching of Sciences focusing on educar by pesquisa
}

\author{
Janice Silvana Novakowski Kierepka (janicekierepka@bol.com.br) \\ Universidade Regional do Noroeste do Estado do Rio Grande do Sul (UNIJUI) \\ Lenir Basso Zanon (bzanon@ unijui.edu.br) \\ Universidade Regional do Noroeste do Estado do Rio Grande do Sul (UNIJUI)
}

\begin{abstract}
Resumo:
Neste texto temos como objetivo identificar limites e possibilidades do Educar pela Pesquisa, particularmente, quanto à problematização de teorias e práticas, na visão de estudantes e professores participantes de um Projeto inserido no PICMEL (Programa de Iniciação em Ciências, Matemática, Engenharias, Tecnologias Criativas e Letras). Na pesquisa foram analisados encontros mensais gravados em áudio de encontros do Projeto realizados entre outubro de 2014 e 2015 . Os encontros foram transcritos, seguindo-se de análise dos turnos de falas, os quais foram organizados em episódios que podem conter indícios da problematização e reconhecimento de teorias e práticas. A investigação segue uma abordagem qualitativa de pesquisa, a partir da análise temática dos conteúdos, conforme Lüdke \& André (2011). Utilizamos para análise a perspectiva histórico-cultural (VIGOTSKI, 2007; 2008). Identificamos nos turnos de fala indícios de problematização de teorias e práticas e de certa evolução de concepções sobre docência. Também de teorias de ensino que estavam em articulação com o Educar pela Pesquisa, indicando a internalização de concepções sobre o Educar pela Pesquisa. Propomos a necessidade de constituir coletivos colaborativos para a problematização conjunta, pois a reflexão é uma capacidade construída e se enriquece pelo diálogo.
\end{abstract}

Palavras-chave: reflexão; diálogo; problemas da prática; internalização.

\begin{abstract}
:
In this text we aim to identify the limits and possibilities of Educating by Research, particularly as to the problematization of theories and practices, in the view of students and teachers participating in the Project inserted in the PICMEL. In the research were analyzed monthly meetings recorded in audio of the Project inserted in the PICMEL, carried out between October 2014 and 2015. The meetings were transcribed, followed by analysis of the turns of speech, which were organized in episodes that may contain indications of the problematization and recognition of theories and practices. The research follows a qualitative research approach, based on the thematic content analysis, according to Lüdke \& André (2011). We use for analysis the historical-cultural perspective (VIGOTSKI, 2007; 2008). We identified in the speech shifts indications of problematization of theories and practices and of a certain evolution of conceptions about teaching. We identified indications that indicated teaching theories that were in articulation with the Educate by the Research, indicating the internalization of
\end{abstract}


conceptions on Educate by the Research. We propose the need to establish collaborative collectives for joint problematization, since reflection is a built capacity and is enriched by dialogue.

Key words: reflection; dialogue; problems of practice; internalization.

\section{INTRODUÇÃO}

A formação de professores é um processo contínuo. É nessa direção que defendemos e investigamos o desenvolvimento de um processo formativo em contexto escolar. Almejávamos que o Projeto inserido no PICMEL (Programa de Iniciação em Ciências, Matemática, Engenharias, Tecnologias Criativas e Letras) pudesse se constituir em um espaço de discussão e reflexão acerca de teorias de ensino sobre o Educar pela Pesquisa e suas relações com práticas dos sujeitos na escola. Consideramos importante a investigação, o diálogo, e reflexão sobre as ações, em que todos os envolvidos assumamse investigadores em um processo colaborativo, que pode impulsionar a transformação de concepções e quiçá de práticas pedagógicas.

A investigação-ação como princípio teórico de formação é proposto por vários autores (ALARCÃO, 2010; CARR, KEMMIS, 1988; CONTRERAS, 1994; ROSA, 2004; GÜLLICH, 2013), com a finalidade de formar professores autônomos, críticos e reflexivos, visando tornar o processo de formação eficiente na transformação da prática em sala de aula. Dessa forma, na investigação-ação os sujeitos pesquisam a própria ação, com objetivo de reconhecer com base em suas teorias os problemas da própria prática docente e enfrentá-los.

A capacidade de reflexão é importante para o reconhecimento e enfrentamento de problemas na prática, e envolve a problematização de teorias e práticas. Em um contexto colaborativo, o processo de reflexão pode ser enriquecido, pelo compartilhamento de ideias. A superação de convicções simplistas e o reconhecimento e enfrentamento de problemas da prática podem ser impulsionados pelo diálogo com outras vozes que provocam a reflexão, sendo a interação entre sujeitos, no processo de investigação-ação, defendida por vários autores (ALARCÃO, 2010; PORLÁN; MARTÍN, 2001; IBIAPINA, 2008; GÜLLICH, 2013).

A importância do reconhecimento e enfrentamento de problemas da prática é parte de vários trabalhos (CARR; KEMMIS, 1988; CONTRERAS, 1994; SCHÖN, 1992; 
NÓVOA, 1992; ROSA, 2004; IMBERNÓN, 2010; PORLÁN; MARTÍN, 2001) que compartilham da defesa da investigação-ação como instrumento potencializador de formação docente. Na pedagogia freireana (FREIRE, 1977; 1989; 1996; FREIRE; FAUNDEZ, 1985), foi possível perceber a relevância concedida à problematização da prática docente.

Com estas considerações sustentando o pressuposto de que a problematização das práticas e teorias possibilita o reconhecimento e enfrentamento de problemas da própria prática docente, o que é um processo necessário para a transformação das ações docentes e que incidem também em revisões nas teorias que guiam a prática, esta investigação foi realizada com o objetivo de: identificar limites e possibilidades do Educar pela Pesquisa, particularmente, quanto à problematização de teorias e práticas, na visão de estudantes e professores participantes do Projeto inserido no PICMEL.

Portanto, investigar esse contexto pode indicar indícios sobre como, e em que medida, pode ter se constituído em um espaço de formação para as professoras participantes, uma autêntica investigação-ação, sendo que era fundamentado em pressupostos da investigação-ação. Buscamos pistas do desenvolvimento da capacidade de analisar, refletir e identificar problemas na própria prática, bem como planejar possibilidades de intervenção.

\section{METODOLOGIA}

A investigação abrange um campo empírico situado em um Grupo de Estudantes e Professores integrantes de um Projeto inserido no PICMEL, desenvolvido em uma escola estadual do município de Guarani das Missões/RS. O Projeto teve início em outubro de 2014 e término em outubro de 2015, e tinha como título "A Pesquisa Científico-escolar na Educação Básica e Reconhecimento da Área de Ciências Biológicas”. Dele participaram seis Estudantes da Educação Básica, duas Professoras Supervisoras, um Professor Orientador/Formador da Universidade Federal da Fronteira Sul (UFFS), uma Professora Formadora (a própria professora pesquisadora participante, voluntária do Projeto e autora neste artigo), e duas Licenciandas bolsistas do programa PIBIDCiências Biológicas (voluntárias do Projeto inserido no PICMEL), em atividade de Iniciação à Docência na escola em que o Projeto era realizado. Por ocasião do início das 
atividades de interação e formação no contexto do PICMEL, foi solicitado o consentimento para participar da investigação, por parte dos sujeitos de pesquisa, quais sejam: duas Professoras Supervisoras Bolsistas (identificadas neste texto como "Sabrina" e "Sandra"), uma Professora Formadora, identificada como "Paula" (a própria professora pesquisadora participante, autora neste artigo) e seis Estudantes de Educação Básica bolsistas do PICMEL (identificadas como "Maria", "Milena", "Miriam", "Franciele", "Fernanda" e "Fabiana"). No Projeto estavam envolvidos também um Professor Orientador/Formador da UFFS e duas Licenciandas bolsistas do programa PIBIDCiências Biológicas (voluntárias do Projeto inserido no PICMEL), porém não foram investigados diálogos, não sendo sujeitos de pesquisa.

Cabe registrar que a presente pesquisa foi desenvolvida de maneira a contemplar todos os preceitos éticos contidos na Resolução 466/12, do Conselho Nacional de Pesquisa, do Ministério da Saúde, no que se refere à pesquisa envolvendo seres humanos. A condição de participação como sujeito de pesquisa foi ser participante do PICMEL de uma escola do município de Guarani das Missões/RS. Utilizamos o termo de consentimento livre e esclarecido (TCLE), resguardando o sigilo dos sujeitos de pesquisa e garantia de retirar o consentimento e informações a qualquer momento se desistir da participação.

O TCLE foi aplicado pela própria pesquisadora no momento da apresentação e explicitação do Projeto junto aos sujeitos envolvidos. Os sujeitos da pesquisa foram orientados quanto às finalidades da pesquisa, riscos, benefícios, o respeito à liberdade em optar ou não pela participação do estudo. Após, foram convidados a assinarem um TCLE, que foi aplicado nas dependências da instituição envolvida. No caso das Estudantes menores de 18 anos, o TCLE foi assinado pelos pais ou responsáveis pelas Estudantes, conforme orientações previstas na Resolução 466/2012. As Estudantes assinaram um Termo de Assentimento. O Pesquisador Principal tem a reponsabilidade pela guarda dos dados da pesquisa em arquivo, físico ou digital, por um período de 5 anos e destino deste material após o término da pesquisa.

Tendo sido consentida a pesquisa, iniciamos a investigação, sendo analisados encontros gravados em áudio do Projeto inserido no PICMEL, produzidos como aporte para a descrição e reflexão sobre as vivências no Projeto. 
Foram realizadas gravações em áudio dos encontros mensais do PICMEL, realizados entre outubro de 2014 e 2015. Para esta pesquisa selecionamos análises obtidas de dois encontros (dias 15 e 22 de outubro de 2015), que tiveram a colaboração da Professora Formadora (Paula). Os encontros foram transcritos, seguindo-se de análise dos turnos de falas, os quais foram organizados em episódios que podem conter indícios da problematização e reconhecimento de teorias e práticas, especialmente sobre: processos de reconhecimento de problemas da própria prática e explicitação de teorias de ensino subjacentes às práticas educativas sobre o Educar pela Pesquisa.

Para a construção dos dados de pesquisa buscamos realizar uma análise cuidadosa por meio de sucessivas leituras pormenorizadas do corpus, com identificação de episódios que sinalizavam indícios que constituiriam focos de discussão com potencialidade de contribuir no processo de elaboração de respostas à questão de pesquisa orientadora do processo de investigação. A fase de seleção dos episódios envolveu ver e rever as gravações várias vezes, seguido de transcrição e classificação dos episódios e turnos de falas (CARVALHO, 2006). Nesse sentido, os episódios selecionados são recortes identificados e analisados de forma a abranger conteúdos temáticos, até aqueles que a princípio pareciam insignificantes.

Nas transcrições das falas dos encontros cada manifestação feita por parte de cada sujeito de pesquisa foi identificada por meio de numeração dos sucessivos turnos de falas referidos como: T1, T2, T3,... Para cada encontro foi usado uma sequência do número 1 até o final dos números expressos.

A investigação segue uma abordagem qualitativa de pesquisa, a partir da análise temática dos conteúdos, conforme Lüdke \& André (2011). Utilizamos para análise a perspectiva histórico-cultural (VIGOTSKI, 2007; 2008).

\section{A PROBlematizaÇÃo de PRÁticas E TEORIAS E O RECONHECIMENTO DE PROBLEMAS DA PRÓPRIA PRÁTICA}

Temos como proposta a importância de o professor assumir postura investigativa sobre a sua atividade docente. Em meio à pesquisa da própria prática, é importante e necessário problematizá-la. Para isso, o professor precisa refletir sobre a sua ação 
(SCHÖN, 1992), caminho pelo qual pode reconhecer problemas em sua prática docente. Do mesmo modo, a reflexão acompanha o processo de superação dos problemas.

Nesse sentido, a reflexão e o diálogo no coletivo auxiliam para a problematização de práticas e teorias, podendo possibilitar o reconhecimento de novas concepções de docência e intervenções pedagógicas. Conforme já discutido, as interações sociais, nesse caso professor-professor, são responsáveis pela constituição do sujeito, que reconstrói as ideias externas, interiorizando-as (VIGOTSKI, 2007).

A partir de encontros do Grupo foi possível construir dados e articular reflexões com teóricos sobre o processo de reconhecimento de problemas da própria prática. Um dos encontros selecionados para análise e discussão nesta pesquisa ocorreu no dia 15 de outubro de 2015. Este teve como temática a leitura e análise do Projeto inserido no PICMEL e contém indícios da temática de interesse: o reconhecimento de problemas da própria prática. Em seguida, são apresentados e analisados os episódios selecionados a partir deste encontro.

No primeiro episódio, Paula buscou no diálogo com o Grupo despertar a reflexão sobre aspectos que surgem a partir da leitura do Projeto.

T 1: é ali traz que é pra trabalhar por áreas de conhecimento que é a proposta agora do Ensino Médio Politécnico... Ciências da Natureza vai trabalhar Biologia... Física e Química junto... integrado... essa integração deveria ser interdisciplinar... [...] é escolher um tema... que é a proposta do ensino médio... que a gente sabe que não tá funcionando acho que bem ainda... (Paula).

T 2: é, isso só funciona quando tiver projetos mesmo... (Sabrina).

T 3: quando tem projetos mesmo porque continua por disciplinas... (Paula).

T 4: é... (Sabrina).

Paula instigou a reflexão sobre a importância da integração entre as disciplinas, como fica evidente no T 1: "é ali traz que é pra trabalhar por áreas de conhecimento que é a proposta agora do Ensino Médio Politécnico". A organização curricular por áreas de conhecimento busca a interdisciplinaridade.

Após, Paula discutiu que, em geral, as escolas não estão ainda conseguindo trabalhar de forma interdisciplinar em forma de questionamento ao Grupo: "a gente sabe que não tá funcionando acho que bem ainda" (T 1), isso provavelmente devido à cultura 
instaurada nas escolas de abordar os conteúdos de forma isolada. Sabrina assinalou: "é, isso só funciona quando tiver projetos mesmo" (T 2).

Cabe ressaltar que a internalização de novos conhecimentos ocorre a partir da interação com o outro na acepção de Vigotski (2008). Em relação ao episódio anterior, percebemos que Sabrina reconheceu a problematização deflagrada por Paula, o que sugere a importância do compartilhamento de ideias para incitar a reflexão sobre assuntos que podem não ser percebidos pelos sujeitos naturalmente, daí a importância da mediação.

O episódio abaixo também foi selecionado do encontro do dia 15 de outubro de 2015

T 5: no externo aprende muito mais... assim fica na... (Sabrina).

T 6: por trás dessas práticas também tinha que ter cuidado para ter ensino dos conceitos... às vezes não dá para ficar muito na prática... na prática... na prática... [...] o professor de química vai trabalhar como pode ser tratado esse es goto... o professor de biologia vai trabalhar o impacto ambiental e as doenças... o professor de física daí eu não sei... alguma coisa... (Paula).

T 7: alguma coisa da física... (Sabrina).

T 8: é... e daí... (Paula).

T 9: pois é... esse... esse é o... é a intenção... (Sabrina).

T 10: [...] em sala de aula o professor não consegue trabalhar essa interdisciplinaridade... ele não consegue... não consegue enxergar como eu vou trabalhar esse saneamento básico na minha disciplina... e na verdade eu acho que é a dificuldade... que a gente vê... (Paula).

T 11: é... (Sabrina).

T 12: de como.... (Paula).

T 13: e... e muitas vezes acaba sendo muito repetitivo... daí um entra na área do outro... e acaba que é uma coisa saturada... (Sabrina).

T 14: é... às vezes vou trabalhar... não... não... (Paula). (Sabrina).

T 15: drogas... todo mundo pega drogas... droga... droga... droga... aí satura...

T 16: mas o professor de Biologia tinha que trabalhar coisa do corpo humano e o professor de química sei lá... a química... de como é... se produz... a forma como é produzido... a fórmula química dessas drogas... algo assim... (Paula).

T 17: é... tem que desenvolver como... (Sabrina).

$[\ldots]$ 
T 19: mais a fundo... da pesquisa... para não se torna repetitivo... (Sabrina).

Sabrina descreveu uma aula ministrada por ela, e após, dialogou: "no externo aprende muito mais" (T 5). Podemos classificar essa análise da professora como um indício de problematização de sua prática, à medida que pensa acerca de suas aulas, descrevendo que estas possibilitam melhor aprendizagem quando incorporam atividades desenvolvidas fora da sala de aula, se referindo à visita realizada a um riacho e à Companhia Riograndense de Saneamento (CORSAN), unidade de Guarani das Missões/RS.

Em seguida à descrição de Sabrina sobre a sua prática, Paula problematizou:

por trás dessas práticas também tinha que ter cuidado para ter ensino dos conceitos... às vezes não dá para ficar muito na prática... na prática... na prática... [...] o professor de química vai trabalhar como pode ser tratado esse esgoto... o professor de biologia vai trabalhar o impacto ambiental e as doenças... o professor de física daí eu não sei... alguma coisa... (T 6).

As discussões podem tornar-se molas propulsoras da reflexão individual, colaborando para a constituição dos sujeitos. Percebemos a provocação de Paula à reflexão acerca da necessidade de articular com a prática os conceitos das disciplinas, concebendo uma abordagem interdisciplinar aos conteúdos. No T 10 isso foi discutido:

"em sala de aula o professor não consegue trabalhar essa interdisciplinaridade... ele não consegue... não consegue enxergar como eu vou trabalhar essa saneamento básico na minha disciplina... e na verdade eu acho que é a dificuldade... que a gente vê... (Paula).

Sabrina concordou, indicando que reconheceu como pertinente a problemática que estava sendo abordada por Paula: “é..." (T 11). Após, comentou problematizando uma realidade que se refere ao contexto geral escolar: "e... e muitas vezes acaba sendo muito repetitivo... dai um entra na área do outro... e acaba que é uma coisa saturada..." (T 13).

Podemos analisar que a partir da descrição de uma prática pedagógica realizada por Sabrina se desenvolveu no Grupo uma reflexão sobre aspectos correlatos ao ensino, como a interdisciplinaridade. Dessa forma, destacamos a importância do coletivo docente para auxiliar na problematização das práticas. Reflexões coletivas podem proporcionar uma discussão sobre ideias, que podem ser aceitas e engendrarem reflexões singulares. 
Após a afirmação de Paula novamente sobre a necessidade de cada disciplina abordar um mesmo tema dentro de suas competências, Sabrina assinalou: "[tem que desenvolver] mais a fundo... da pesquisa... para não se tornar repetitivo.” (T 19). Identificamos uma alternativa de enfrentamento ao problema da abordagem superficial de um tema, para que não se torne repetitivo entre as disciplinas. Segundo a concepção de Sabrina, os docentes precisam aprofundar a pesquisa. Assim, preparar aulas em que se articulem conceitos da disciplina de regência com o tema de estudo, é a necessidade do planejamento. É importante que o professor se constitua pesquisador para poder envolver e educar os alunos pela pesquisa, formando sujeitos críticos e reflexivos, à medida que também domina habilidades (ALARCÃO, 2010).

No episódio abaixo foi possível identificar mais indícios, além da pesquisa do professor que implica em planejamento, de possibilidades para o desenvolvimento de práticas interdisciplinares:

T 28: às vezes também é difícil... (Paula).

T 29: eu acho que a geração agora que vem a de vocês... se preparando mais... eu acho que vai dá certo sabe... porque eles já tão sendo preparados um pouco diferente do que da nossa geração... professores que tão chegando agora... eu acho que são mais preparados... (Sabrina).

T 30: não sei é... tem que tomar cuidado para quando cai... de te várias horas... (Paula).

T 31: é... (Sabrina).

T 32: é que é a pressão de ter uma turma... ter outra... (Paula).

T 33: não tem tempo... (Sabrina).

T 34: sobrecarrega... (Paula).

$[\ldots]$

T 36: a gente sabe [...] eu já conheço como é que é a realidade... então não dá pra... pegar uma turma de quarenta alunos... eu vou se o professor de Seminário Integrado no... eu vou trabalhar a pesquisa com cada um daqueles alunos... também é dificil... um aluno pega um tema... outro pega outro... pega tema importantes... o professor conseguir orientar... teria que ter... ter conhecimento... acredito de cada um desses tema... (Paula).

T 38: ou... ou seria de todos os professores se reunir e ter um momento assim de... de discussão... vamos dizer uma manhã... os ciclos formativos nos outros... nas outras... terças-feiras que seria o grupo... por área... (Sabrina).

Sabrina, no T 29, deixou explícito: 
eu acho que a geração agora que vem a de vocês... se preparando mais... eu acho que vai dá certo sabe... porque eles já tão sendo preparados um pouco diferente do que da nossa geração... professores que estão chegando agora... eu acho que são mais preparados...

Dessa forma, Sabrina afirmou que um problema são as limitações na formação, assinalando que é necessário o preparo do professor. Quando Sabrina discutiu a formação, faloudos professores em geral, e também de sua própria formação. Porém, apontou como possibilidade a preparação durante a formação inicial e propomos também a importância da formação contínua, subsidiado por maior valorização da profissão docente. Depreendemos da análise a necessidade de preparação/formação do professor, bem como a aceitação da necessidade do contínuo processo de reflexão e aprimoramento do processo de ensino, com a adoção de novas propostas durante a carreira.

Em meio à discussão deflagrada por Paula sobre a sobrecarga de trabalho, Sabrina propôs o problema da falta de tempo para estudos e planejamento: "não tem tempo" (T 33). Provavelmente com base na convicção, já analisada no discurso, de que a articulação das disciplinas é difícil de efetivar nas escolas, Paula discutiu uma dificuldade do professor do SI, que traz a proposta de incorporar a pesquisa no ensino: "também é difícil... um aluno pega um tema... outro pega outro... pega tema importantes... o professor conseguir orientar... teria que ter... ter conhecimento... acredito de cada um desses tema...” (T 36). O que precisa ser buscado pelas escolas é a integração das disciplinas com o tema de pesquisa dos alunos do SI, para que as temáticas sejam abordadas de forma mais aprofundada, com professores de várias áreas, por exemplo. Após a reflexão de Paula, que tinha como objetivo provocar a discussão, Sabrina afirmou: "ou... ou seria de todos os professores se reunir e ter um momento assim de... de discussão... vamos dizer uma manhã... os ciclos formativos nos outros... nas outras... terças-feiras que seria o grupo... por área..." (T 38). Esse turno de fala nos apresenta indícios do reconhecimento da relevância do diálogo, do planejamento conjunto entre professores de uma mesma área de conhecimento e da necessidade do grupo de formação. Ainda indica que Sabrina propõe o desenvolvimento de comunidades reflexivas (ALARCÃO, 2010), à medida que sugere a discussão na escola. 
4. A EXPLICITAÇÃO DE TEORIAS DE ENSINO SUBJACENTES Às PRÁTICAS EDUCATIVAS SOBRE O EDUCAR PELA PESQUISA

Propomos que o reconhecimento e enfrentamento de problemas da própria prática ocorrem por meio da reflexão como caminho formativo. Bem como, é possibilitada ao sujeito a tomada de consciência das teorias que guiam a sua prática, especialmente na reflexão compartilhada que pode tornar explícita as teorias ao sujeito (PORLÁN; MARTÍN, 2001).

Pôde ser identificado, em turnos selecionados do encontro do Grupo constituído pelos integrantes do PICMEL realizado no dia 22 de outubro de 2015, compreensões dos sujeitos de pesquisa sobre o Educar pela Pesquisa. Este encontro teve como tema a leitura do texto "Educar pela Pesquisa: exercício de aprender a aprender" (MORAES, 2002), como método para desencadear a discussão e reflexão, a fim de identificar indícios de concepções sobre pesquisa. Indícios sobre concepções de pesquisa são perceptíveis em vários trechos, que evidenciam alternativas de Educar pela Pesquisa que estão de acordo com princípios de autores como Demo (2000), Moraes (2002) e Galiazzi (2003), sendo selecionados alguns para discussão. No episódio abaixo, podem ser analisadas as concepções sobre pesquisa implícitas nas falas dos sujeitos:

T 1: diferente de... de outros anos... o tempo que a gente estudava é bem diferente... porque hoje o aluno só não quer... de fazer pesquisa... porque tem tanto... (Sabrina).

T 2: tem de tudo... (Franciele).

T 3: material... (Sabrina).

T 4: tem tudo... (Franciele).

T 5: tem tanta... (Sabrina).

T 6: antigamente não tinha... (Franciele).

$[\ldots]$

T 7: então... esse é o objetivo da pesquisa... eu acho que os alunos de hoje... não sei se era antigamente [...] não querem pensar... (Paula).

T 8: é... querem receber pronto... (Sabrina).

T 9: eles querem receber pronto... (Paula).

T 10: eu acho que sempre tem que... aquela vontade... (Sabrina).

T 11: é que hoje assim ó... tem computador na escola... tem de tudo... tem o livro... (Franciele). 
T 12: acho que é chegar aí copiar... colar... e entregar... (Sabrina).

T 13: copiar e colar e deu... (Paula).

T 14: mas tem que ver vários sites... (Sabrina).

T 15: mas eu também não gosto de lê às vezes... (Franciele).

T 16: não fazem porque que não querem por que.... (Sabrina).

T 17: mas tem que ler... (Paula).

T 18: pois é... (Sabrina).

T 19: mas é isso o que o projeto tá falando... construir seus próprios argumentos com base naquilo que tu lê... a primeira fase é a cópia... porque tu não vai inventar nada do nada... mas precisa de uma fonte... mas depois tem que entender o que tá lendo... (Paula).

T 20: juntar várias fontes... (Sabrina).

T 21: várias fontes... (Paula).

T 22: vê se bate... os mesmos resultados... se é realmente é... para você tirar uma conclusão... (Sabrina).

T 23: é... (Paula).

T 24: isso é um aprendizado... o aprendizado precisa... (Sabrina). (Paula).

T 25: isso que é o aprendizado... porque a pesquisa de... de copiar... ainda...

T 26: porque o que nós temos nos livros didáticos ali... já tá prontinho ali... alguém escreveu... trouxe ali... vocês aplicam essa aula aí para nós... mas... se argumenta isso? É... realmente é isso? (Sabrina).

T 27: é o professor ir blá... blá... blá... (Paula).

T 28: é... bem fácil... (Sabrina)

Paula, no T 7, dialogou: "eu acho que os alunos de hoje... [...] não querem pensar...". Sabrina concordou, dizendo: "é... querem receber pronto..." (T 8). Desse modo, percebemos concepções diferentes do ensino tradicional, que alunos e professores encontram-se geralmente habituados, à medida que é criticada a passividade do estudante. Isso pode indicar o reconhecimento de concepções do Educar pela Pesquisa, à medida que as ideias dialogam. O Educar pela Pesquisa vinha sendo estudado pelo Grupo, podendo ter dado sustentação às críticas. Elas reclamam também a necessidade de uma nova concepção do papel do aluno e do professor.

No turno 12, Sabrina criticou: "acho que é chegar aí copiar... colar... e entregar...", e conclui: "mas tem que ver vários sites..." (T 14). Nesses trechos se evidenciam teorias de ensino que superam as visões de pesquisa como reprodução de 
conteúdos de outras fontes, se restringindo ao nível de cópia. Desse modo, percebemos também a superação de visões de aprendizagem como "assimilação passiva do conhecimento ensinado" (GALIAZZI, 2003, p. 155).

Paula buscou no diálogo reafirmar as concepções sobre pesquisa, comentando: “mas é isso o que o projeto tá falando... construir seus próprios argumentos com base naquilo que tu lê... a primeira fase é a cópia... porque tu não vai inventar nada do nada... mas precisa de uma fonte... mas depois tem que entender o que tá lendo..." (T 19). A professora ressaltou que na pesquisa o aluno precisa construir seus próprios argumentos, a partir da compreensão do que lê. Sabrina complementou: "juntar várias fontes..." (T 20) e "vê se bate... os mesmos resultados... se é realmente é... pra você tirar uma conclusão...” (T 22). Isso evidencia o necessário protagonismo dos educandos no processo pedagógico. E aponta o modo de organização da sala de aula de forma a priorizar a participação de todos, em que o professor constitui-se mediador e o aluno assume a responsabilidade de participar na construção de seus conhecimentos, de forma a exercer a sua autonomia (DEMO, 2000).

Sabrina ressaltou que é necessário que o aluno formule suas próprias conclusões sobre o tema de pesquisa, e conclui: "isso é um aprendizado... o aprendizado precisa..." (T 24). Dessa forma, é possível perceber a visão do aluno como sujeito ativo no processo de ensino (DEMO, 2000). "A essência do pesquisar está centrada no fazer, nas interpretações e elaborações próprias" (FRISON, 2002, p. 146).

Demo (2000) propõe que o Educar pela Pesquisa não apresenta receitas para serem aplicadas em aula pelos professores, ao invés disso, cada processo de pesquisa deve ser formulado e reencaminhado por cada professor. Sabrina criticou o papel dos livros didáticos, por trazerem tudo "prontinho", aulas que devem ser aplicadas pelos professores: "porque o que nós temos nos livros didáticos ali... já tá prontinho ali... alguém escreveu... trouxe ali... vocês aplicam essa aula aí para nós... mas... se argumenta isso? É... realmente é isso?" (T 26). A argumentação sobre as aulas propostas pelo livro didático, defendido por Sabrina, indica a reflexão e discussão, em conjunto com os alunos, concedendo ao estudante a possibilidade de elaboração própria (DEMO, 2000). Em meio à crítica ao uso do livro didático como material incontestável, tanto pelo professor, para o desenvolvimento da prática pedagógica, quanto pelo aluno, como fonte segura e 
completa de conhecimentos, no próximo episódio Sabrina dialogou sobre a grande disponibilidade de informações:

T 29: alguma fonte... e hoje meu... para apresentar um trabalho... tanta coisa boa... e ontem a gente assistiu lá... as meninas com aquelas apresentações... isso é tão bonito... tão cheio de vida aquilo... a gente tinha que escreve em cartazes... imagina tempo que nós levava para fazer uma apresentação... horas e horas escrevendo... fazendo um cartaz... para apresentar... e hoje vão lá e clicam... copiam e colam... (Sabrina).

T 30: nem lê... (Paula).

T 31: nem lê... o que que é isso... (Sabrina).

T 32: isso não é pesquisa... se o professor pede uma pesquisa... isso não é pesquisa... (Paula).

T 33: isso não é pesquisa... (Sabrina).

T 34: acho fico tudo muito fácil... quem sabe seja isso... (Paula).

T 35: não sei tá tudo muito prontinho assim... nem na... (Sabrina).

Percebemos a preocupação de Sabrina em relação à disponibilidade das informações, "tanta coisa boa" (T 29), que conduz a reprodução copiada, "e hoje vão lá e clicam... copiam e colam..." (T 29). O acesso facilitado às informações deveria provocar os estudantes a consultar vários sites, selecionar e reconstruir os conhecimentos de forma própria, porém isso geralmente não ocorre na visão de Sabrina. No entanto, este é um dos fatores que acarretam a necessidade de capacitar os alunos a serem críticos e reflexivos, para que assim tornem-se aptos a selecionar as informações veiculadas pelos meios de comunicação e tenham a capacidade de opinar (ALARCÃO, 2010).

Paula é mais rigorosa e afirmou que quando há falta de leitura séria e reconstrução dos argumentos não é pesquisa: "isso não é pesquisa... se o professor pede uma pesquisa... isso não é pesquisa..." (T 32). Ou não está de acordo com a sua concepção de pesquisa, que se apresenta em concordância com pressupostos do Educar pela Pesquisa, como a importância do questionamento e construção de argumentos (MORAES; GALIZZI; RAMOS, 2002, p. 231). Dessa forma, percebemos dois pressupostos do Educar pela Pesquisa, a leitura e escrita. A importância da leitura e da sistematização escrita pôde ser percebida no episódio abaixo, que contém a descrição de uma prática pedagógica desenvolvida por Sabrina:

T 36: sabe pra ter uma ideia... hoje eu fui fazer hoje de manhã... com o sexto ano o trabalho sobre as camadas da atmosfera... e daí eles... [...] eles fizeram a leitura do 
capítulo... discussão e tudo... e depois no final eu disse... agora vocês peguem uma folha no caderno e agora vocês desenhem... façam representação através do desenho as cinco camadas ali... como... como é... simplesmente ligeirinho foram lá... viraram as páginas... acharam lá um esquema... copiaram aquele esquema... e é isso... eu disse não... isso eu não quero... não é isso que eu pedi... eu botei o desenho e coloquem alguns itens...onde tem oxigênio... onde tem mais... sabe onde... que acontecem todas as... os gases e tudo... aí eles ficaram assim... não sabiam como fazer... e o que fazer... e entregaram aquele esquema que estava na mão pronto... aí eles começaram a fazer... começaram a entender... começaram a colocar tudo no desenho... e pesquisando... e vendo... contando... depois no final eles disseram... agora sim... a gente aprendeu isso... assim os alunos... sabe... (Sabrina).

Percebemos o reconhecimento da relevância da leitura, discussão e reconstrução própria dos conhecimentos (GALIAZZI, 2003, p. 95), como pôde ser identificado no turno 36: "eles fizeram a leitura do capítulo... discussão e tudo... e depois no final eu disse... agora vocês peguem uma folha no caderno e agora vocês desenhem... façam representação através do desenho as cinco camadas ali... como... como é..." (Sabrina), o que indica a compreensão destes pressupostos do Educar pela Pesquisa. O desenho proposto aos alunos exigia que fossem sistematizados os conhecimentos.

A tendência à cópia também pôde ser identificada no turno 36: "simplesmente ligeirinho foram lá... viraram as páginas... acharam lá um esquema... copiaram aquele esquema... e é isso..." (Sabrina, T 36). Porém, a professora não aceitou a cópia, solicitando que refizessem a atividade, e os alunos concluíram que foi melhorado o aprendizado dos conceitos: "aí eles começaram a fazer... começaram a entender... começaram a colocar tudo no desenho... e pesquisando... e vendo... contando... depois no final eles disseram... agora sim... a gente aprendeu isso... assim os alunos... sabe..." (Sabrina, T 36). Dessa forma, reiteramos a importância de envolver os alunos na reconstrução dos conhecimentos (DEMO, 2000; GALIAZZI, 2003).

No episódio abaixo novamente puderam ser identificados indícios que indicam a relevância dos alunos consultarem outras fontes, além do livro didático. Paula descreveu uma aula em que solicitou aos alunos que selecionassem ideias sobre um assunto para confeccionarem um cartaz:

T 37: e se eles fossem pesquisar sobre tudo aquilo... ampliassem... (Sabrina).

T 38: entrar mais a fundo... (Fernanda). 
T 39: não só naquele... numa página do livro... e se eles fossem pegar outras fontes... pesquisassem... e será que é isso... não... se é aquilo... trazer bem... (Sabrina).

T 40: mas como mudar essas mentalidades aí... (Paula).

$[\ldots]$

T 41: se é trabalho para casa... não só aquela página do livro... (Sabrina).

[...]

T 42: você tem que ver várias fontes... (Sabrina).

T 43: eu já falo antes... nós vamos fazer um cartaz... nós estamos estudando platelmintos... então eu vou explicar ali... as... as características gerais... e aí eu já do antes... esse grupo vai fazer sobre essa doença... e vocês trazem que vocês vão colocar no cartaz... a ideia é pesquisar várias fontes e trazer as ideias já selecionadas... quem disse que trazem... (Paula).

T44: não trazem... (Sabrina).

T 45: e daí isso é uma maneira de trabalhar por uma pesquisa... (Paula).

T 46: é uma pesquisa... (Sabrina).

T 47: é trazer... é selecionar... (Paula).

T 48: é... (Sabrina).

T 49: de alguma forma... entender aquilo... e depois quando vai apresentar o cartaz vai ter que saber falar... construir o próprio conhecimento sobre aquilo... (Paula).

Na fala de Sabrina foi possível identificar indícios da relevância da participação do aluno no processo de pesquisa, à medida que propôs que os alunos buscassem informações: "e se eles fossem pesquisar sobre tudo aquilo... ampliassem..." (T 37). Ampliar o que está proposto no livro didático pode implicar também na problematização deste conhecimento, identificando lacunas que podem ser ampliadas pelos estudantes. No T 39 isso pôde ser mais claramente evidenciado, à medida que Sabrina propôs que os estudantes se questionem: "não só naquele... numa página do livro... e se eles fossem pegar outras fontes... pesquisassem... e será que é isso... não... se é aquilo... trazer bem..." (T 39).

Paula descreveu uma prática de confecção de cartazes na prática de ensino sobre platelmintos e propôs a relevância de "pesquisar várias fontes e trazer as ideias já selecionadas..." (T 43). A seleção de ideias importantes sobre um assunto pelos estudantes, além de implicar em autonomia, exige leitura e escrita a partir da seleção, que aponta também o papel da criticidade. No T 49, Paula explicitou a relevância de "de 
alguma forma... entender aquilo... e depois quando vai apresentar o cartaz vai ter que saber falar... construir o próprio conhecimento sobre aquilo...". Pôde ser identificada a valorização da leitura, escrita e comunicação dos resultados. Destacamos a aproximações com ideias do Educar pela Pesquisa, como o protagonismo do aluno e a reconstrução de conhecimentos (DEMO, 2000; GALIAZZI, 2003).

\section{CONSIDERAÇÕES FINAIS}

A problematização é um conceito necessário e central na formação inicial, continuada e no ensino escolar. Propomos a necessidade de constituir coletivos colaborativos para a problematização conjunta, pois a reflexão é uma capacidade construída e se enriquece pelo diálogo. Em relação ao Grupo constituído na escola por meio da proposta do PICMEL, concluímos que aos poucos foi se constituindo reflexivo, em que as leituras e discussões foram trazendo inquietações tanto às professoras que poderiam pensar sobre as suas práticas como para as Estudantes que analisavam as práticas de seus professores em suas vivências escolares. Porém, a análise dos diálogos do Grupo nos possibilitou perceber a insistência da amiga crítica em provocar reflexões a partir de entendimentos sobre referenciais do Educar pela Pesquisa, o que nos permite afirmar que teve papel central no surgimento de reflexões compartilhadas pelo coletivo. Isso reitera a importância dos contextos colaborativos, corroborando a nossa hipótese inicial de que o professor tem dificuldades para problematizar a sua prática e suas teorias, o que implica no não reconhecimento de problemas, que só ocorre por meio de aproximação com referenciais teóricos, à medida que as leituras e provocações da Professora Formadora (Paula) se mostraram fundamentais para a problematização das práticas e teorias.

Identificamos nos turnos de fala indícios de problematização de teorias e práticas e de certa evolução de concepções sobre docência, à medida que foram discutidas propostas de planejamento e desenvolvimento do ensino por áreas de conhecimento, como alternativa à dificuldade de abordar os conteúdos de forma interdisciplinar, que nos apresentava como um problema da prática docente. Dessa forma, no diálogo surgiram sugestões propostas pelos sujeitos, donde depreendemos a importância das interações docentes possibilitadas em contextos colaborativos. Nesse sentido, concluímos que o 
diálogo possibilitou a vivência de atitudes reflexivas, o reconhecimento de problemas da prática docente e a proposição de novas intervenções, que reitera a nossa hipótese inicial de que a reflexão crítica compartilhada possibilita o reconhecimento e enfrentamento de problemas da prática docente.

Os episódios discutidos permitiram identificar indícios que indicavam teorias de ensino que estavam em articulação com o Educar pela Pesquisa, indicando a internalização de concepções sobre o Educar pela Pesquisa. Defendemos que isso foi se tornando possível a partir de leituras e discussão de referenciais, reflexões e produção de artigos científicos pelo Grupo. Propomos que o coletivo formado pelos integrantes do Projeto inserido no PICMEL foi determinante, conjuntamente com as leituras, para a explicitação e reconstrução de teorias de ensino subjacentes às práticas educativas sobre o Educar pela Pesquisa, pois as concepções muitas vezes não conscientes pelo próprio sujeito, sendo que o diálogo no Grupo era conduzido pela Professora Formadora (Paula) que tinha o intuito de desencadear a reflexão sobre aspectos do Educar pela Pesquisa. Isso reitera a nossa hipótese inicial de que o professor tem dificuldade para problematizar as suas teorias de ensino e que a reflexão crítica compartilhada transforma teorias de docência, impulsionando a internalização de conceitos e constituição de práticas refletidas, que são aperfeiçoadas de forma autônoma e colaborativa.

As reflexões empreendidas nesta pesquisa nos permitem reafirmar o pressuposto de que a problematização da prática e teorias possibilitam o reconhecimento e enfrentamento de problemas da própria prática docente, que é um processo necessário para a transformação das ações docentes e que incidem também em revisões nas teorias que guiam a prática. A problematização de práticas e teorias pode ser realizada em conjunto pelos professores da escola, constituindo-se a escola em uma comunidade reflexiva. Bem como, a categoria problematização também pode ser norteadora do planejamento das aulas, situando-se a prática em torno da solução de problemas de forma colaborativa, priorizando as interações sociais que se oportunizam em sala de aula. E, para isso, o ensino pode ser orientado pelo Educar pela Pesquisa.

\section{REFERÊNCIAS}


ALARCÃO, Isabel. Professores reflexivos em uma escola reflexiva. 7. ed. São Paulo: Cortez, 2010.

CARR, Wilfred; KEMMIS, Stephen. Teoria crítica de la enseñanza: investigaciónacción en la formación del profesorado. Barcelona: Martinez Roca, 1988.

CARVAlHO, Ana Maria Pessoa de. Uma metodologia de pesquisa para estudar os processos de ensino e aprendizagem em salas de aula. p. 13-47. In: SANTOS, Flávia Maria Teixeira dos; GRECA, Ileana María (org). A pesquisa em ensino de ciências no Brasil e suas metodologias. Ijuí: Ed. Unijuí, 2006. - 440 p. - (Coleção educação em ciências). ISBN 85-7429-528-0.

CONTRERAS, José Domingo. La investigación en la acción. Cuadernos de Pedagogia, no 224, Madrid: Morata, abril 1994, p. 7-31.

DEMO, Pedro. Educar pela Pesquisa. - 4 ed. Campinas, São Paulo: Autores Associados, 2000.

FREIRE, Paulo. Educadores de rua. Uma abordagem crítica. Alternativas de atendimento aos meninos de rua. UNICEF, julho, 1989. Impresso em Colômbia pela Editorial Gente Nueva. Bogotá.

Extensão ou comunicação? Tradução de Rosisca Darcy de Oliveira / prefácio de Jacques Chonchol. Rio de Janeiro, Paz e Terra, 1977.

; FAUNDEZ, Antonio. Por uma Pedagogia da Pergunta. - Rio e Janeiro: Paz e Terra, 1985. (Coleção Educação e Comunicação: v. 15).

Pedagogia da autonomia: saberes necessários à prática. - São Paulo: Paz e Terra, 1996. - (Coleção Leitura).

FRISON, Lourdes Maria Bragagnolo. Pesquisa como Superação da Aula Copiada. In: MORAES, Roque; LIMA, Valderez Marina do Rosário (orgs.). Pesquisa em sala de aula: Tendências para a educação em novos tempos. Porto Alegre: EDIPUCRS, 2002.

GALIAZZI, Maria do C. Educar pela Pesquisa: ambiente de formação de professores de ciências. Ijuí: Ed. UNIJUÍ, 2003.

GÜLLICH, Roque Ismael da Costa. Investigação-Formação-Ação em Ciências: um caminho para reconstruir a relação entre livro didático, o professor e o ensino. Curitiba: Editora Prismas Ltda, 2013.

IBIAPINA, I. M. L. de M. Pesquisa colaborativa: investigação, formação e produção de conhecimentos. Brasília: Líber Livro Editora, 2008.

IMBERNÓN, F. Formação continuada de professores. Porto Alegre: Artmed, 2010, $120 \mathrm{p}$. 
LÜDKE, Menga; ANDRÉ, Marli E. D. A. Pesquisa em educação: abordagens qualitativas. São Paulo: EPU, 2011.

MORAES, Roque. Educar pela Pesquisa: exercício de aprender a aprender. In: MORAES, Roque; LIMA, Valderez Marina do Rosário (orgs.). Pesquisa em sala de aula: Tendências para a educação em novos tempos. Porto Alegre: EDIPUCRS, 2002.

; GALIAZZI, Maria do Carmo; RAMOS, Maurivan G. Pesquisa em sala de aula: fundamentos e pressupostos. In: MORAES, Roque; LIMA, Valderez Marina do Rosário (orgs.). Pesquisa em sala de aula: Tendências para a educação em novos tempos. Porto Alegre: EDIPUCRS, 2002.

NÓVOA, A. Formação de professores e profissão docente. In: NÓVOA, António. Os professores e a sua formação. 2 ed.1992.

PORLÁN, Rafael; MARTÍN, José. El diario del profesor: um recurso para investigación em el aula. Díada: Sevilla, 2001.

RAMOS, Maurivan Güntzel. Educar pela Pesquisa é Educar para a Argumentação. In: MORAES, Roque; LIMA, Valderez Marina do Rosário (orgs.). Pesquisa em sala de aula: Tendências para a educação em novos tempos. Porto Alegre: EDIPUCRS, 2002.

ROSA, Maria Inês de Freitas Petrucci dos Santos. Investigação e ensino: articulações e possibilidades na formação de professores de ciências. Ijuí: Ed. Unijuí, 2004. 184p.

SCHÖN, Donald A. Formar professores como profissionais reflexivos. 1992. In: NÓVOA, António. Os professores e a sua formação. 2. ed. Portugal: Ed. Porto, 1992.

VIGOTSKY, L.S. A Formação Social da Mente: o desenvolvimento dos processos psicológicos superiores. São Paulo: Martins Fontes, 2007. Org. Michael Cole [et al.]. Trad. José Cipolla Neto, Luís Silveira Menna Barreto, Solange Castro Afeche, 7. ed.

Pensamento e Linguagem. São Paulo: Martins Fontes, 2008. Trad. de Jefferson Luiz Camargo, 4. ed. 